\title{
Type II Vitamin D Dependent Rickets: A Case Report
}

\author{
Malla KK ${ }^{1}$, Malla ${ }^{2}$, Shaw $\mathrm{C}^{3}$, Thapalial $\mathrm{A}^{4}$ \\ ${ }^{1}$ Dr. Kalpana K Malla, MBBS, MD, Associate Professor, ${ }^{2} \mathrm{Dr}$. Tejesh Malla MBBS, MD, Assistant Professor, \\ ${ }^{3}$ Dr. Chandan Shaw, MBBS, MD, Assistant Professor, ${ }^{4}$ Dr. Anna Thapalial, MBBS, MD, Professor and Head of Department \\ of Paediatrics. All from the Department of Paediatrics, Manipal College of Medical Sciences, Pokhara, Nepal.
}

Address for correspondence: Dr. Kalpana K Malla, E-mail: kalpana17@hotmail.com

\begin{abstract}
Vitamin D-dependent rickets Type II is a rare autosomal recessive disorder. Alopecia of the scalp or the body is seen in some families with Vitamin D-dependent rickets Type II. We report a child with this disease, and review the salient features of this disease with emphasis on the associated alopecia. Due to lack of facilities for estimation of $1,25(\mathrm{OH})_{2} \mathrm{D}$ and parathyroid hormone, alopecia remains the only clue to the diagnosis of this rare syndrome in association with resistant rickets.
\end{abstract}

Key words: Rickets, Vitamin D metabolism

\section{The Case}

$A^{s}$ six year old male hailing from Tanahun presented to us with complaint of falling of primary dentition and bowing of legs since the time he started to walk. $\mathrm{He}$ also had history of falling of hair after the neonatal period and his milestones were delayed. He was the only issue of consanguineous parents. On examination, he had features of florid rickets with bowing of legs (genu varum), coxa vara, widened wrist and hot cross bun appearance of head. (Fig.1) Occipitofrontal circumference (OFC) was $50 \mathrm{~cm}$. He had alopecia totalis (Fig. 2). He was short statured with a height of $82 \mathrm{~cm}$, [expected $119 \mathrm{~cm}$ (ht/age $=70 \%$ which is severe stunting)] and had a waddling gait. Rachitic rosary, Harrison sulcus and profound myopathy the characteristic features of calcium deficient rickets, was not present in this case. Most of the teeth had fallen off. In the remaining teeth there were pulp deformities and periapical infections. His biochemical parameters were in favour of advanced rickets showing hypocalcemia (serum calcium - 7mg/ $\mathrm{dl})$, serum phosphate normal $(4 \mathrm{mg} / \mathrm{dl})$, raised alkaline phosophatase level of $4200 \mathrm{IU}$ and the renal functions were within normal limits. Blood gas analysis revealed slight metabolic acidosis with $\mathrm{pH} 7.30, \mathrm{HCO}_{3}$ level $18 \mathrm{mEq} / \mathrm{L}$ and base deficit of 5.1 . His roentgenographic findings revealed: metaphyseal flaying, fraying, and cupping of proximal, distal tibia, distal femur, radius and ulna (Fig. 3 and 4). Due to lack of facilities and poor financial background of the patient, level of $1,25(\mathrm{OH})_{2}$ $\mathrm{D}$, and parathormone level could not be assessed. Child was treated with high dose 1- alpha-hydroxy-vitamin D3. He was on periodic follow up and showed improvement on X-rays and biochemical parameters but unfortunately he did not come for further follow ups due to their fmilial problems. This treatment schedule should continue for a long time till improvement is seen. 


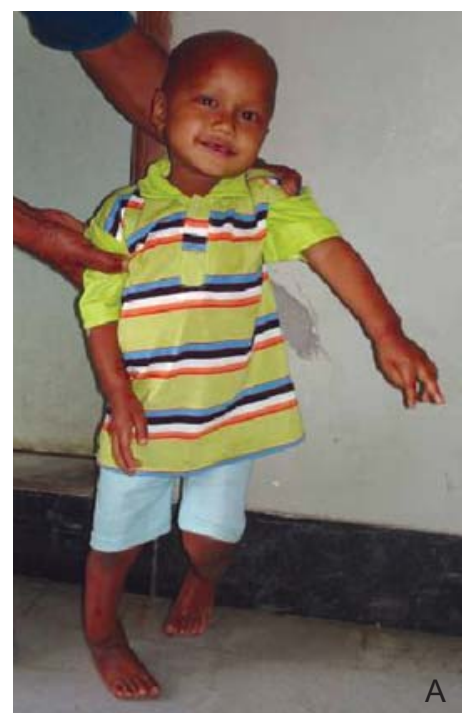

Fig. 1 ( $A$ and $B$ ) : Features of florid Rickets bowing of leg.

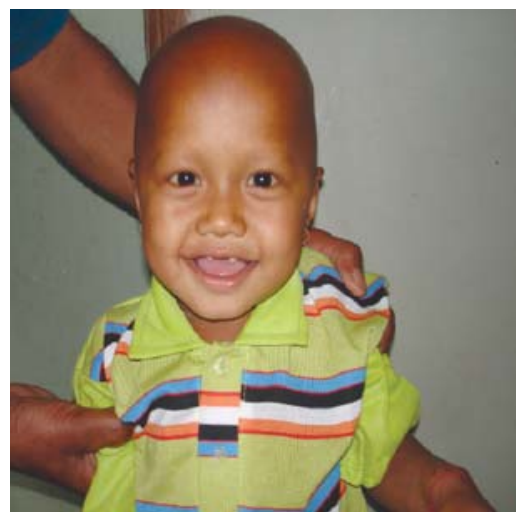

Fig. 2: Showing Alopecia Totalis

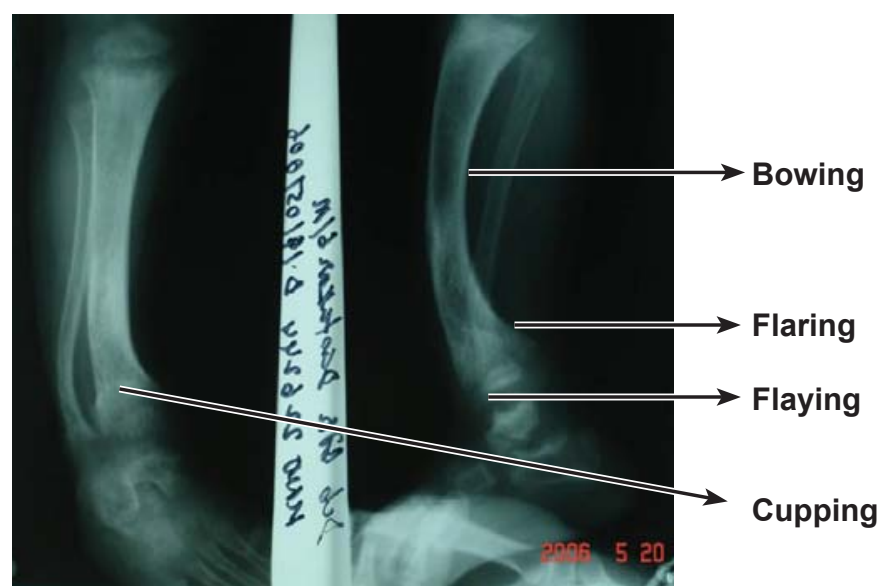

Fig. 3: X-ray forearm with wrist showing Bowing, Cupping, Flaring and Flaying.

\section{Discussion}

Hreditary 1, 25-dihydroxyvitamin D resistant rickets (HVDRR) known as vitamin D dependent rickets type II is a rare autosomal recessive disease that arises as a result of mutations in the gene encoding the Vitamin D receptor ${ }^{1}$. It usually presents with rachitic changes not responsive to Vitamin $D$ treatment with elevated circulating levels of 1,25-dihydroxyvitamin $D_{3}$. This is caused by target organ resistance to $1,25(\mathrm{OH})_{2} \mathrm{D} 3$ associated with an abnormality of tissue receptors. ${ }^{2}$ This results in inadequate intestinal absorption of calcium, possibly accompanied by deranged vitamin $\mathrm{D}$ action in other organs.

Though this is a rare disease, cases from various part of the world has been reported. Five cases of vitamin D-dependent rickets type II with alopecia was reported from Japan ${ }^{3}$. Two siblings with vitamin

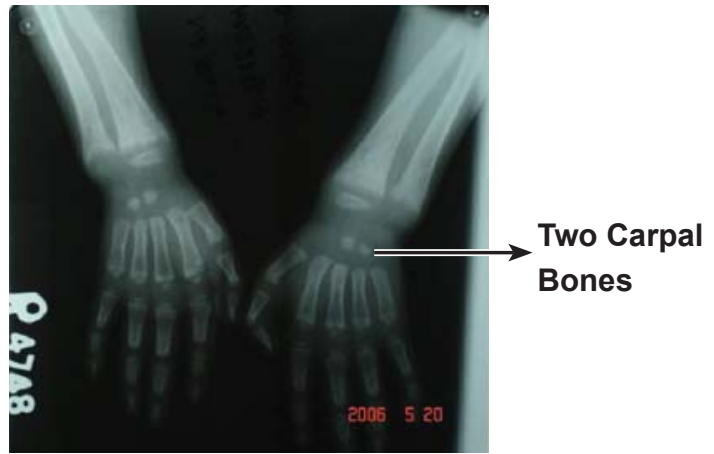

Fig. 4: X-Ray of the hand showing delayed bone age.

D dependent type II rickets were reported for the first time from India in $1990^{4}$. Another case of vitamin D dependent rickets (Type II) with alopecia in a five year old child was reported by Feldman D, Chen T, Cone C, Hirst M, Shani S, Benderli A, Hochberg Zin. ${ }^{5}$ Our case also had total alopecia. Pathogenesis of rickets is based on disorder in Vitamin D metabolism. Vitamin D is made available to the body both by intestinal absorption and by photosynthesis in the skin. To be active, vitamin $D$ must be hydroxylated to 25- $(\mathrm{OH}) \mathrm{D}$, principally in the liver, and to $1,25(\mathrm{OH})_{2} \mathrm{D}$ and $24,25(\mathrm{OH})_{2} \mathrm{D}$, principally in the kidney. The best studied target tissues for the vitamin $\mathrm{D}$ metabolites are bone, kidney, and intestine. However, the list of additional potential target tissues is expanding and includes muscle, endocrine pancreas, parathyroid gland, pituitary, and $\operatorname{skin}^{5}$. Disorders of the vitamin D endocrine system can be categorized into three groups: 
decreased bioavailability, abnormal metabolism, and aberrant target tissue response. Vitamin $D$ dependent rickets type II is the best example of aberrant target tissue response ${ }^{6}$. 1alpha, $25(\mathrm{OH})_{2} \mathrm{D}_{3}$ transcriptionally controls the expression of a particular set of target genes mediated through nuclear vitamin $\mathrm{D}$ receptor(VDR) acting as a ligand-inducible factor. Two types of vitamin D-dependent hereditary rickets (VDDR) are known to be caused by mutations in the 1 alpha hydroxylase and VDR genes. The 1 alpha hydroxylase genes is responsible for VDDR type I, and VDR for type II. Both of the diseases display an autosomal-recessive trait. VDDR II consists of a spectrum of intracellular vitamin $D$ receptor (VDR) defects and is characterized by the early onset of severe rickets and associated alopecia. This can be attributed to mutations in the VDR gene ${ }^{7}$.

Children with this rickets typically present with bowing of lower extremities related to weight bearing at the age of walking. Rachitic rosary, Harrison groove, profound myopathy, the characteristic of calcium deficient rickets are not evident. They have waddling gait and with genu varum, genu valgum, coxa vara and short stature. Adult height of untreated patient is $130-165 \mathrm{~cm}^{8}$. Pulp deformities and lesions called intraglobular dentin are characteristic tooth abnormalities and periapical infections are usually present. Our patient presented with the similar findings.

Cupping, flaying, fraying of metaphysis and generalized osteopenia is characteristic feature on Roentgenographic study. X-ray wrist of our patient had all these features (Fig 3) along with delay in bone age (Fig.4). Biochemically serum calcium is normal or slightly reduced $(9-9.4 \mathrm{mg} / \mathrm{dl})$, serum phosphate moderately reduced $(1.5-3 \mathrm{mg} / \mathrm{dl})$ and serum alkaline phosphatase (ALP) markedly elevated. Raised ALP activity is the first laboratory abnormality. Parathroid hormone level is elevated due to secondary hyperparathyroidism. Serum level of $1,25(\mathrm{OH})_{2} \mathrm{D}$ is elevated. Aminoaciduria and glucosuria is also present. There is renal tubular bicarbonate wasting and renal tubular acidosis as a result blood gas analysis shows metabolic acidosis. The molecular basis of the unresponsiveness of these cells is due to defective or absent $1,25(\mathrm{OH}) 2 \mathrm{D} 3$ receptors $^{5}$.

Massive doses of vitamin D analogs and calcium supplementation is usually required for the treatment. However, the response to therapy is sometimes variable ${ }^{9}$. There was healing of severe rickets despite hypocalcemia in two siblings with absent vitamin $D$ receptors. Long periods of treatment with excessive doses of vitamin $D$ led to relative hypoparathyroidism and a return to normal of calcium metabolism during calcitriol treatment. This finding suggests that some other regulating factor may substitute for the defective vitamin $D$ receptor ${ }^{10}$. Rickets reported in a 3-year-old boy and his 1-year-old sister, both with alopecia, was cured by treatment with 50,000 IU of vitamin $D_{2}$ daily for 2 years and did not recur within 14 years after cessation of therapy ${ }^{11}$. Three patients were reported with clinically different severities of vitamin D-dependent rickets type II with alopecia, were treated with large doses of 1 alpha- hydroxyl-vitamin D3 (1 alpha- $(\mathrm{OH}) \mathrm{D}_{3}$ ) and $2 \mathrm{~g}$ of calcium lactate. Except for the alopecia, all of the abnormalities of patients 1 and 2 were reversed by treatment with 3 micrograms $/ \mathrm{kg} / \mathrm{d}$ of 1 alpha- $(\mathrm{OH}) \mathrm{D} 3$, and those of patient 3, who had the severest manifestations, were reversed by treatment with 6 micrograms $/ \mathrm{kg} / \mathrm{d}^{12}$. Calcification of the teeth, size of the teeth and dental arches, facial growth and calcification of the carpal bones were studied in three children with clinically of different severities of vitamin D-dependent rickets (VDDR) type II with alopecia. It was observed that abnormally large pulp chambers and thin dentin could be corrected by effective medication ${ }^{13}$. Our patient with dental problem is expected to do better on treatment for rickets.

In conclusion Vitamin in D-dependent rickets type II with alopecia is a rare disease and is resistant to Vitamin D treatment. Treatment is often unsatisfactory, but it may respond to massive doses of active vitamin $D$ metabolites like1 alpha-hydroxy-vitamin D3. Since some cases respond to treatment, it is important to treat this disease whenever diagnosed as the outcome can be excellent.

\section{References}

1. Tokita A, Hisada K, Nishizawa K. Bone Disease with Vitamin D Receptor Abnormality. Nippon Rinsho. 2002; 60:385-90.

2. Sultan Al-Khenaizan, Vitale P. Vitamin D-dependent Rickets Type II with Alopecia: Two Case Reports and Review of the Literature. Int J Dermato 2003; 42:682-685.

3. Widhalm K, Waldhauser F, Zwiauer K. Transient vitamin-D dependent Rickets? A Case Report Differential Diagnosis. Padiatr Padol. 1982; 17:40916.

4. Gupta PC, Patwari AK, Mullick DN. Alopecia with Rrickets: An End Organ Unresponsiveness to 1, 25-dihydroxyvitamin D--A Case Report. Indian J Med Sci 1990; 44:239-243.

5. Feldman D, Chen T, Cone C, Hirst M, Shani S, Benderli A, Hochberg Z. Vitamin D Resistant 
Rickets with Alopecia: Cultured Skin Fibroblasts Exhibit Defective Cytoplasmic Receptors and Unresponsiveness to 1, 25(OH) 2D3. J Clin Endocrinol Metab 1982; 55:1020-1022.

6. Bikle DD. The Vitamin D Endocrine System. Adv Intern Med 1982; 27:45-71.

7. Kato S, Yoshizazawa T, Kitanaka S, Murayama A, Takeyama K. Takeda E, Yamamoto H, Taketani Y, Miyamoto K. Vitamin D-Dependent Rickets Type I and Type II. Acta Paediatr Jpn 1997; 39:508-513.

8. Behrman R.E, Kliegman R.M \& Jenson H.B. Nelson Text Book of Pediatrrics 16 th Edition 2000; W.B Saunders Company, Harcourt Asia Pte Ltd; 21362137.

9. Takeda E, Yamamoto H, Taketani Y, Miyamoto K. Vitamin D-Dependent Rickets Type I and Type II. Acta Paediatr Jpn 1997; 39:508-513.
10. Kruse K, Feldmann E. Healing of Rickets during Vitamin D Therapy despite defective Vitamin D Receptors in two Siblings with Vitamin D-Dependent Rickets Type II. J Pediatr 1995; 126:145-148.

11. Takeda E, Yokota I, Kawakami I, Hashimoto T, Kuroda Y, Arase S. Two Siblings with Vitamin-DDependent Rickets Type II: No Recurrence of Rickets for 14 years after Cessation of Therapy. Eur J Pediatr 1989; 149:54-57.

12. Takeda E, Kuroda Y, Saijo T, Naito E, Kobashi H, Yokota I, Miyao M. 1 alpha-hydroxyvitamin D3 Treatment of three patients with 1, 25dihydroxyvitamin D-Receptor- Defect Rickets and Alopecia. Pediatr 1987; 80:97-101.

13. Nishino M, Kamada K, Arita K, Takarada T. Dentofacial Manifestations in Children with Vitamin D-Dependent Rickets Type II Shoni Shikagaku Zasshi. 1990; 28:346-358. 